Document downloaded from:

http://hdl.handle.net/10251/59812

This paper must be cited as:

Desantes Fernández, JM.; Benajes Calvo, JV.; García Oliver, JM.; Kolodziej, CP. (2014). Effects of intake pressure on particle size and number emissions from premixed diesel lowtemperature combustion. International Journal of Engine Research. 15(2):222-235. doi:10.1177/1468087412469514.

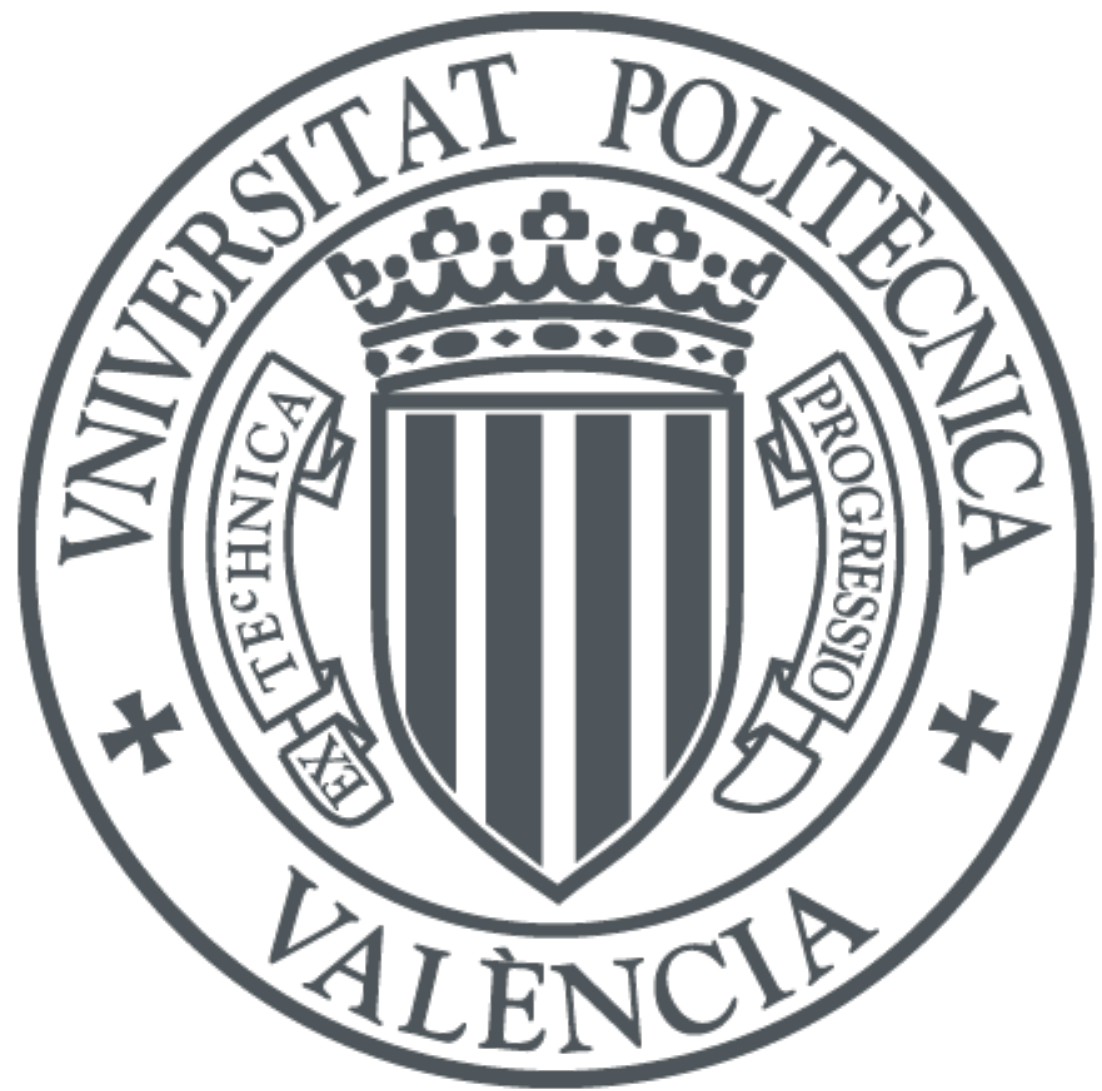

The final publication is available at

http://dx.doi.org/10.1177/1468087412469514

Copyright SAGE Publications (UK and US)

Additional Information 


\title{
Effects of Intake Pressure on Particle Size and Number Emissions from Premixed Diesel Low Temperature Combustion
}

\section{(Intake Pressure on Diesel Particle Emissions)}

\author{
José M. Desantes, Jesús Benajes, José M. García-Oliver, Christopher Kolodziej* \\ CMT - Motores Térmicos, Universidad Politécnica de Valencia, Camino de Vera s/n, Valencia, Valencia 46022 \\ SPAIN \\ Keywords: Premixed, Low Temperature Combustion, Emissions \\ * Corresponding Author. Telephone: +34-963877007. Fax: +34-963877659. E-mail addresses: \\ chko@mot.upv.es, ckolodziej@hotmail.com (C. Kolodziej).
}

\begin{abstract}
In this study, ten premixed Diesel Low Temperature Combustion engine operating conditions were chosen based on engine intake pressure (1.2 - 1.6 bar), intake oxygen concentration (10\%, 11\%, and 12\%), and injection timing ( $-24^{\circ}$ aTDC in all cases). At each intake oxygen concentration, the effect of intake pressure on combustion parameters and emissions measurements (carbon monoxide, hydrocarbons, nitrogen oxides, particulate matter mass concentration, and particle size distributions) was analyzed. Although increased intake pressure resulted in higher in-cylinder charge air density which improved fuel-air premixing and late-cycle oxidation quality, higher intake pressure also advanced the start of combustion (SOC) and thereby decreased the time available for fuel and air premixing. But even with the decrease in premixing time available before SOC, increased intake pressure caused significant decreases in carbon monoxide, hydrocarbon, particulate matter (PM) mass, and particle number emissions. Particle size distribution measurements allowed greater understanding of how higher intake pressure decreased the PM mass concentrations with respect to particle size. To further investigate the experimental results, a OD engine heat release code was used to analyze combustion temperatures and a 1D free spray model was used to estimate the relative levels of liquid fuel spray impingement on the piston surface and maximum local equivalence ratio at SOC for each test case. Therefore, though the premixing time was shortened by higher intake pressures, the decreased emissions were understood by combined effects of enhanced fuel and air premixing quality and much improved late-cycle oxidation near the end of combustion.
\end{abstract}

\section{INTRODUCTION}

Increasingly stringent Diesel engine emissions regulations introduced in recent years (and those still to come) have motivated a great deal of research into reduced emissions premixed combustion concepts, emissions characterization, and aftertreatment systems. One of the common trends seen in modern Diesel engine combustion research has been the reduction of oxides of nitrogen $\left(\mathrm{NO}_{\mathrm{x}}\right)$ through lower combustion temperature, achieved by the use of exhaust gas recirculation (EGR) into the engine intake system. Reduction of particulate matter (PM) emissions has been simultaneously achieved by reducing the local fuel-air equivalence ratios during the combustion process.[1-9] One method of realizing these objectives at the same time has been through the use of EGR to reduce the intake oxygen concentration and advance the start of injection (SOI), thus allowing separation of the injection and combustion events. These longer ignition delays provide longer premixing times for the fuel and air before the start of combustion (SOC) in order to reduce the maximum local equivalence ratios during the combustion process. In this way, premixed Diesel low temperature combustion (LTC) can simultaneously provide greatly reduced engine-out $\mathrm{NO}_{\mathrm{x}}$ and $\mathrm{PM}$ emissions.

One consequence of the reduction in combustion temperature (necessary for reduction of $\mathrm{NO}_{\mathrm{x}}$ emissions) has been the increase of unburned hydrocarbon $(\mathrm{HC})$ and carbon monoxide (CO) emissions. Various researchers have demonstrated the possibility of greatly decreasing $\mathrm{HC}$ and $\mathrm{CO}$ emissions, while maintaining very low $\mathrm{NO}_{x}$ and PM mass emissions, through increased intake pressure to enhance the in-cylinder fuel-air mixing and combustion.[18,19, 35-42]

Two understandings of $\mathrm{HC}$ emissions from premixed combustion have been proposed.[19] The first possible source of $\mathrm{HC}$ emissions is from under-mixed regions which don't allow sufficient mixing with the available oxygen for the fuel to fully combust. These under-mixed regions could come from the fuel jet structure left after the end of combustion or from overlaps in adjacent fuel sprays. Another example of how these under-mixed regions could be formed is by liquid fuel deposits on the combustion chamber surfaces from reduced gas density at the early injection timings. Kashdan, et al. have also suggested a mechanism of how liquid fuel deposited on the piston can later flash-boil due to the rapid in-cylinder pressure reduction occurring during the opening of the 
exhaust valve and facilitating expulsion of the $\mathrm{HC}$ emissions with the exhaust gases.[41] Increased intake pressure promotes higher mixing rates and shorter spray liquid length, thus in general better mixing the fuel with the available oxygen.

The second way in which higher intake pressure decreases $\mathrm{HC}$ emissions deals with over-mixed regions of fuel and air in the combustion chamber due to relatively long periods of fuel and air premixing. Increased intake pressures have been shown to advance the start of combustion (for same SOI). Since relatively longer ignition delays create these over-mixed regions, reductions to the ignition delay by higher intake pressure also reduce the formation of these over-mixed regions in the combustion chamber. Thus HC emissions from these sources are also diminished.

Reduced $\mathrm{CO}$ emissions are also proposed in the literature by two possible pathways. Similar to the HC emissions from over-mixed regions, $\mathrm{CO}$ is also only partially oxidized in these regions. Decrease of the ignition delay with increased intake pressure provides less time for fuel and air premixing (fewer over-mixed regions with equivalence ratio less than 1 ) before the start of combustion and therefore this limits the $\mathrm{CO}$ emissions. The literature has also shown through calculations that $\mathrm{CO}$ oxidation rates are faster in these over-mixed regions with higher intake pressure. This means that higher intake pressure not only reduces the quantity of over-mixed regions, but also increases the $\mathrm{CO}$ oxidation rates in those over-mixed regions which would still be formed.

Though researchers have reported very low $\mathrm{NO}_{x}$ and PM mass emissions at the same time as greatly reduced $\mathrm{HC}$ and $\mathrm{CO}$ emissions for increased intake pressure, there is a need for more information on how intake pressure affects particle size and number emissions within the premixed Diesel LTC operating regime.[10-17] Going from conventional diffusive Diesel combustion to premixed Diesel combustion concepts, it has been shown that one can greatly reduce PM mass emissions in the premixed Diesel LTC regime but at the same time possibly greatly increase the particle number emissions. Therefore it is the objective of this research to investigate how intake pressure affects particle size and number emissions between premixed Diesel engine operating conditions.

It is hoped in this work that by investigating in greater detail the emissions emitted from potential future low emissions premixed combustion concepts that further information can simultaneously be provided to researchers from engine combustion, emissions, and aftertreatment groups to help produce the most efficient overall Diesel engine system.

\section{EXPERIMENTAL SETUP}

\subsection{RESEARCH ENGINE}

Characteristics of the single-cylinder research engine can be found in Table 1. Reducing the engine from its full multi-cylinder version to the single-cylinder research version allowed for very precise and steady control of the low temperature combustion engine operating conditions. Comparing measurements of the exhaust emissions with the in-cylinder combustion measurements were also simplified with the single-cylinder engine in that there was no mixing of emissions from other cylinders.

Table 1. Research Engine Characteristics.

\begin{tabular}{|c|c|}
\hline Engine Type & $\begin{array}{c}\text { Four-stroke, Direct } \\
\text { Injection, Single-Cylinder }\end{array}$ \\
\hline Bore $x$ Stroke [mm] & $123 \times 152$ \\
\hline Displacement [liter] & 1.806 \\
\hline Compression Ratio [-] & $14.4: 1$ \\
\hline Valve Timing ['aTDC] & $\begin{array}{r}{ }^{\circ} \text { IVO 375 / IVC 535 } \\
\text { EVO 147 / EVC 347 }\end{array}$ \\
\hline
\end{tabular}

The injection system shown in Table 2 contained a high pressure common rail system as well as a pressure amplified piston solenoid injector. More details of this injector can be seen in [20]. The piston geometry and injector nozzle pairing was selected after tests with multiple piston and injector nozzle combinations throughout the entire engine load and speed range. In the end, these piston and injector nozzle geometries were the most versatile for all engine operating conditions.

Table 2. Injection System Characteristics.

\begin{tabular}{|c|c|}
\hline Injection System & $\begin{array}{c}\text { Common-Rail } \\
\text { Pressure Amplified Piston } \\
\text { Solenoid Injector }\end{array}$ \\
\hline Injector Nozzle & Mini-Sac, $7 \times 0.190 \mathrm{~mm}$ \\
\hline Nozzle Flow & 840 \\
\hline
\end{tabular}




\begin{tabular}{|c|c|}
\hline [cc/30sec at 100 bar] & \\
\hline Included Angle & $120^{\circ}$ \\
\hline
\end{tabular}

A schematic of the engine research facility used in this work is displayed in Figure 1. Compressed air was supplied to the engine by an oil-free screw compressor and dehumidification system. Heat exchangers and electrical heaters were also used in the fresh intake air and EGR loops to provide best control of the engine intake conditions. Intake, exhaust, and EGR settling chambers were used to dampen pressure waves created by the single-cylinder engine. An electro-pneumatically controlled exhaust back pressure valve was used to drive the EGR loop and simulate exhaust pressure conditions similar to those with a turbocharger in place. The emissions sampling ports were placed downstream of the exhaust back pressure valve, where the exhaust pressure was approximately atmospheric. The partial exhaust dilution system was placed upstream of the gas analyzer and smokemeter sampling ports to allow them to perform purge operations independent of particle size distribution measurements.

An in-cylinder piezo-electric pressure transducer allowed for recording and averaging of 50 engine cycles for each test point. Five repeatability measurements were performed for each test point, which were later postprocessed using a OD combustion diagnosis code.

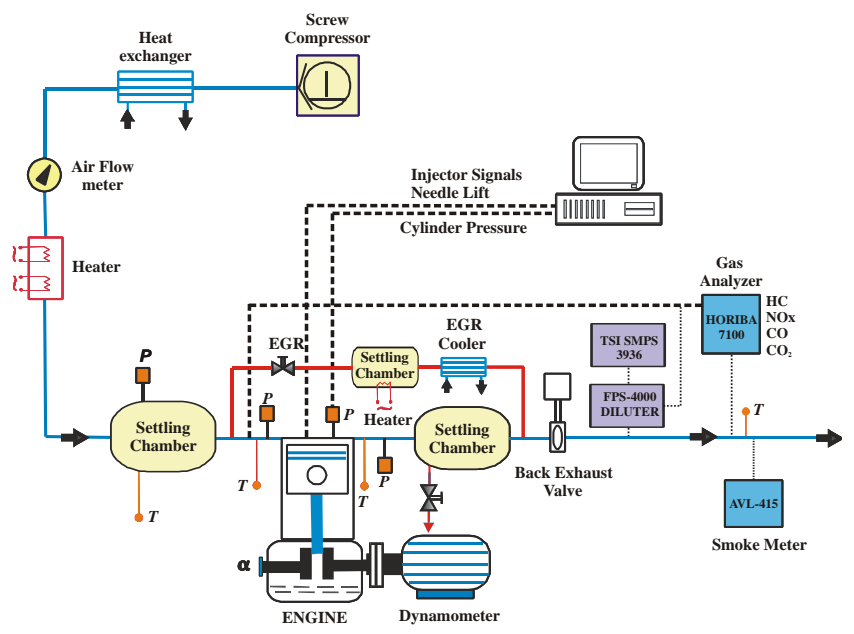

Figure 1. Design of Engine Research Laboratory.

\subsection{DIESEL FUEL}

Specifications of the European Diesel test fuel associated with its combustion and emissions characteristics are shown in Table 3. All of these fuel characteristics fall within the regulations established for sale of commercial Diesel fuel in Europe. Fuel sulfur and polycyclic aromatic hydrocarbon content (PAH) are shown due to their relation with engine-out particle emissions.[25-29]

Table 3. Relevant Test Fuel Characteristics

\begin{tabular}{|c|c|}
\hline Cetane Number & 53.5 \\
\hline Sulfur Content [ppm] & 8.9 \\
\hline PAH Content $[\%$ (mass/mass)] & 1.3 \\
\hline T95 $\left[{ }^{\circ} \mathrm{C}\right]$ & 356 \\
\hline
\end{tabular}

\subsection{ENGINE TEST CONDITIONS}

The 10 engine operating conditions chosen to test the effects of intake pressure on engine performance and emissions in premixed Diesel LTC are displayed in Table 4. The duration needed for injection of the $70 \mathrm{mg}$ of fuel per combustion stroke was 8.25 crank angle degrees (CAD). With a real SOI of $-22.47^{\circ}$ aTDC $\left(-24^{\circ}\right.$ aTDC electronic command), the end of injection (EOI) occurred at $-14.22^{\circ}$ aTDC for all test cases. Cases 1,2 , and 3 corresponded to $12 \%, 11 \%$, and $10 \%$ intake oxygen concentration. The maximum global fuel-air equivalence ratio allowed was set to 0.88 . Therefore the minimum intake pressure of each test case was determined by the respective case's intake oxygen concentration setting and this maximum equivalence ratio. The maximum intake pressure of each test case was decided to be 1.6 bar, as this was seen as a feasible intake pressure for the full multi-cylinder version of this test engine, given the other operating parameters. Slight increases were seen in the gross indicated mean effective pressure $\left(\mathrm{IMEP}_{\mathrm{g}}\right)$ with increased intake pressure. 


\begin{tabular}{|c|c|c|c|}
\hline Case & 1 & 2 & 3 \\
\hline$P_{\text {intake }}[\mathrm{bar}]$ & $1.2-1.6$ & $1.32-1.6$ & $1.46-1.6$ \\
\hline $\begin{array}{l}\text { Speed } \\
\text { [RPM] }\end{array}$ & 1200 & 1200 & 1200 \\
\hline $\mathrm{IMEP}_{\mathrm{g}}[\mathrm{bar}]$ & $7.28-7.46$ & $7.41-7.6$ & $7.28-7.52$ \\
\hline $\begin{array}{l}\mathrm{X}_{\mathrm{O} 2 \text {,intake }} \\
\text { [\%_vol] }\end{array}$ & 12 & 11 & 10 \\
\hline EGR [\%_vol] & $45.8-54$ & $50.9-56.3$ & $56.6-59$ \\
\hline$\Phi[-]$ & $0.86-0.74$ & $0.88-0.8$ & $0.88-0.83$ \\
\hline $\begin{array}{c}\mathbf{m}_{\text {fuel }} \\
{[\mathrm{mg} / \mathrm{stk}]}\end{array}$ & 70 & 70 & 70 \\
\hline SOI ['aTDC] & -24 & -24 & -24 \\
\hline$P_{\text {injection }}[\mathrm{bar}]$ & 1450 & 1450 & 1450 \\
\hline $\mathbf{T}_{\text {intake }}\left[{ }^{\circ} \mathrm{C}\right]$ & 45 & 45 & 45 \\
\hline $\mathrm{T}_{\text {exhaust }}\left[{ }^{\circ} \mathrm{C}\right]$ & $391-329$ & $372-334$ & $349-332$ \\
\hline$P_{\text {exhaust }}$ [bar] & $1.3-1.7$ & $1.42-1.7$ & $1.56-1.7$ \\
\hline
\end{tabular}

\subsection{EMISSIONS MEASUREMENT}

\subsubsection{Gaseous and PM Mass Emissions}

Gaseous exhaust emissions of carbon dioxide $\left(\mathrm{CO}_{2}\right)$, carbon monoxide $(\mathrm{CO})$, total hydrocarbons $(\mathrm{HC})$, and oxides of nitrogen $\left(\mathrm{NO}_{\mathrm{x}}\right.$ ) were measured with a Horiba MEXA-7100. A second CO2 analyzer was used to determine the engine intake EGR rate as well as the exhaust dilution ratio. Particulate matter mass concentration emissions were measured by an AVL 415 Smokemeter.

\subsubsection{Exhaust Dilution}

The exhaust gases must be diluted with filtered and dried compressed air before measurements of the particle size distribution can be performed.[31] In these tests, a Dekati FPS-4000 two-stage partial dilutor was used for exhaust dilution. The dilution process decreases the saturation ratio of vaporous species (such as water and $\mathrm{HC}$ species) in the exhaust sample so to mitigate their condensation on, and change of, the existing particles from the engine combustion. In this way, performing the exhaust sample dilution attempts to preserve the particle compositions as close as possible to how they existed in the exhaust stream. The dilution strategy used in these tests was based on this objective, to best conserve the exhaust PM sample as close as possible to how it existed in the exhaust stream and would likely enter into an aftertreatment system (although it should be clarified that no aftertreatment system was used during these tests). Therefore all tests used a heated primary dilution as close to isothermal with the exhaust sample temperature as possible and a larger ambient temperature secondary dilution to cool and maintain the exhaust particle composition. The total dilution ratio was maintained higher than 70:1 in all tests to minimize condensation of volatile material after the exhaust sample left the exhaust system. Initial tests prior to these experiments showed that variation in the total dilution ratio above 70:1 had insignificant effects on the particle size distribution measurements for these engine operating conditions, thus giving confidence that particle size distribution effects reported in this study were associated to the changes in engine operating conditions.

\subsubsection{Particle Size Distribution Measurement}

Particle size distributions were measured of the diluted engine exhaust from $7.64 \mathrm{~nm}$ to $289 \mathrm{~nm}$ by a TSI Scanning Mobility Particle Sizer (SMPS) 3936. This measurement system is composed of a TSI 3080L long differential mobility analyzer (DMA) electrostatic classifier and a TSI Condensation Particle Counter (CPC) 3010. The DMA electrostatic classifier is used to select the electrical mobility diameter of the particles permitted to pass to the CPC, where the particle concentration at that size is determined. Performing the same particle number concentration measurement at each electrical mobility diameter within the selected size range allows for creation of the particle size distribution. The electrical mobility diameter range of this work was $7.64 \mathrm{~nm}$ to $289 \mathrm{~nm}$, based on a DMA $1 \mathrm{lpm}$ sample flow and a $10 \mathrm{lpm}$ sheath flow. Multiple baseline tests were performed in which the DMA scan up and scan down times were varied independently to find the respective times which most accurately represented the LTC PM particle size distributions. In the end, a scan up time of 100 seconds and scan down time of 60 seconds were chosen. The size distributions plotted in the Results and Discussion section were number-weighted and normalized to one decade of particle size (dN/dlogDp) by the TSI SMPS software. The advantage of these normalized particle size distribution units is that they can be compared to measurements from other particle size distribution instruments, independent of measurement channel resolution. Corrections for particle multiple charging and diffusional losses within the SMPS measurement system were also performed by the TSI software.[32]

\section{CALCULATIONS}




\subsection{THERMODYNAMIC ANALYSES}

Instantaneous pressure signal data (averaged over 50 combustion cycles) were post-processed by a OD combustion diagnosis code, CALMEC, to determine the evolution of the in-cylinder pressure and rate of heat release (RoHR).[21,22] A maximum value of the adiabatic flame temperature was calculated based on a local equivalence ratio equal to 1 (stoichiometric) and constant pressure at each step of the calculation. A 13-specie equilibrium approach was followed for the adiabatic flame temperature calculation, as developed by Way et al.[23]

\subsection{SPRAY ANALYSES}

Fuel injection rate profile characterization was performed using a commercial fuel injection test rig based on the Bosch system.[24] From these measurements the instantaneous injection rate, actual liquid start of injection, and real liquid end of injection could be determined. Using these injection rate profiles and the in-cylinder pressure and density up to the start of the main combustion event, in-cylinder mixing properties of the fuel and charge air (even after the end of injection) could be modeled. For this purpose, a 1D mixing-controlled inert Diesel spray model was used to perform this simulation.[33,34] This model has already been used in previous premixed Diesel LTC particle emissions investigations as well.[35]

The 1D spray model allowed qualitative analysis of the maximum fuel-air equivalence ratio from the end of injection to the start of the high temperature heat release (HTHR), relative fuel-air equivalence ratio at the start of combustion $\left(\Phi_{\mathrm{SOC}}\right)$, and relative maximum spray liquid length during the injection process. One difference between this free spray model and the in-cylinder combustion conditions is that the model simulates the spray and pre-combustion mixing development in a large open volume, such that combustion chamber surface effects (such as the piston bowl) are not taken into account. For this reason, the results obtained from the model are used on a qualitative basis, discussing differences between tests on a relative basis.

Figure 2 shows the relationship between the trajectory of the fuel spray at the moment of the real start of fuel injection $\left(-22.47^{\circ} \mathrm{aTDC}\right)$ with respect to the position of the piston bowl at that moment. If the fuel spray were to have hypothetically reached its maximum liquid spray length instantaneously at SOI, and assuming it was long enough, it would have intersected the piston bowl surface at the indicated position. In reality, the development of the fuel spray is not instantaneous due to various fluid dynamic effects and requires some milliseconds to reach its maximum liquid spray length. Therefore it follows that the real liquid spray and piston bowl surface intersection position would be slightly lower in the piston bowl than the indicated position due to the upward movement of the piston during the time required to develop the fuel jet.

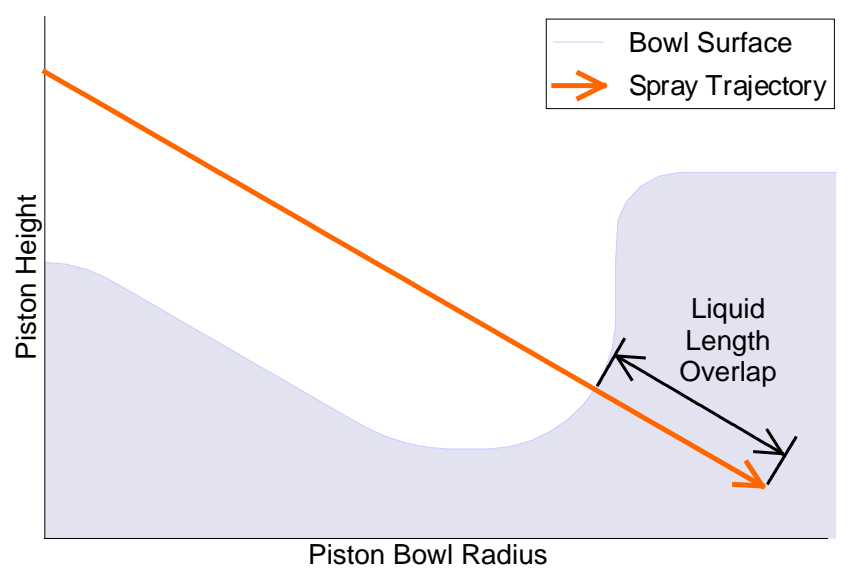

\section{Figure 2. Fuel Spray Trajectory Relative to Piston Bowl at -24ªTDC Electronic Command Injection} Timing.

Once the free jet fuel spray model calculates the maximum liquid length, this distance can be compared to the distance available in the combustion chamber at that moment between the injector nozzle and the piston bowl surface (LL Overlap). The spray liquid length overlap is determined from the distance by which the modeled liquid fuel jet exceeds the distance available in the combustion chamber to the piston bowl surface. This value can then be used as an approximation to compare the relative amounts of liquid fuel deposited on the piston bowl surface in each of the engine test cases.

Figure 3 shows another benefit of the 1D free spray model. It is possible to monitor the maximum local fuel-air equivalence ratio $\left(\Phi_{\text {MAX }}\right)$ after the end of injection, until the start of the HTHR. Although this parameter doesn't take into account the effects of interactions between the fuel spray and combustion chamber surfaces, it does provide useful information regarding the relative quality of fuel-air premixing in the main area of the combustion chamber before SOC between each of the engine test points. The data represented in Figure 3 comes from post-analysis calculations of the Case 1 intake pressure test points (12\% intake oxygen concentration) from the 
end of injection until the start of the HTHR. It follows that the local $\Phi_{\text {MAX }}$ of all intake pressure test points, approximated by the free spray model, decreased remarkably quickly (exponentially) from infinity during the injection to a $\Phi_{\text {MAX }}$ below 3 in less than $1.1 \mathrm{~ms}$. Due to the increased charge air density, the 1.6 bar intake pressure test condition arrived $25 \%$ faster to a $\Phi_{\text {MAX }}$ of 3.0 than the 1.21 bar intake pressure condition. But, as will be examined later, the $0.2 \mathrm{~ms}$ longer ignition delay of the 1.21 bar intake pressure operating condition allowed the $\Phi_{\text {MAX }}$ at SOC to decrease $15 \%$ lower than that of the 1.6 bar intake pressure condition ( $\Phi_{\text {MAX }}$ at SOC from 2.9 to 2.5). This simplified analysis of the fuel-air premixing in the main area of the combustion chamber (not including wall effects) supports how important even small increases in the ignition delay (0.2 ms in Case 1) can be beneficial to increased fuel-air premixing and reducing the local $\Phi_{\mathrm{MAX}}$ before SOC.

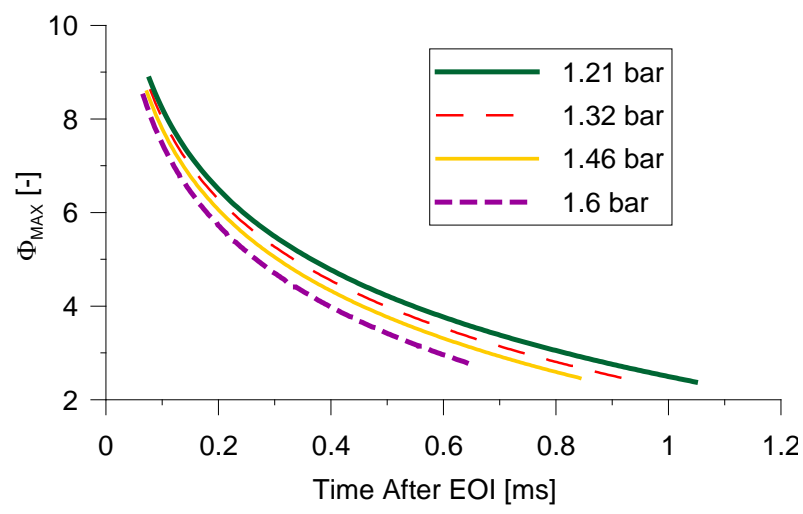

Figure 3. Development of Free Spray Mixing for Case 1 Intake Pressures After End of Injection.

\section{RESULTS AND DISCUSSION}

\subsection{COMBUSTION ANALYSES}

Instantaneous combustion information of the in-cylinder pressure and rate of heat release (RoHR) for each test case is shown in Figure 4, Figure 5, and Figure 6. As can be seen by the in-cylinder pressure curves before the start of combustion, higher engine intake pressures led to higher in-cylinder pressures during the compression stroke. This increased in-cylinder pressure led to increased charge air density and thus faster mixing rates. Faster mixing rates led to the formation of regions with auto-ignition potential faster, thus slightly advancing the SOC. These small advances in the start of the main combustion HTHR caused increases in the maximum incylinder pressure. Evidence of low temperature exothermic reactions before the main HTHR was evident in each case.

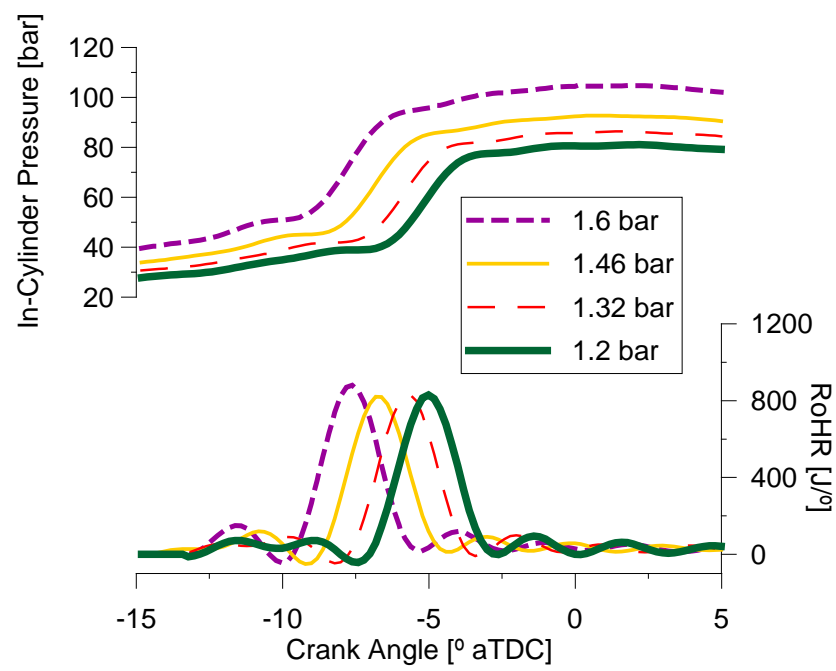

Figure 4. Instantaneous Combustion Data of Case 1 with 12\% Intake Oxygen Concentration. 


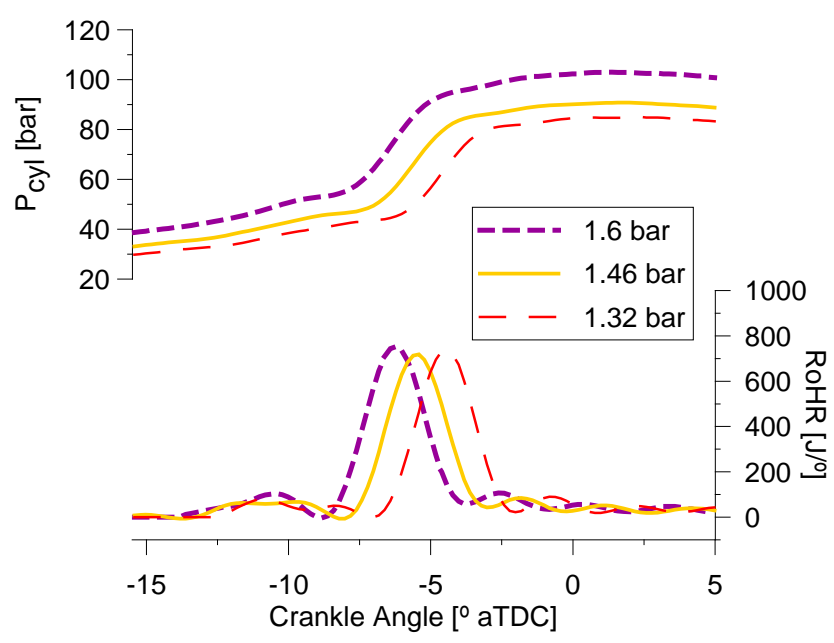

Figure 5. Instantaneous Combustion Data of Case 2 with 11\% Intake Oxygen Concentration.

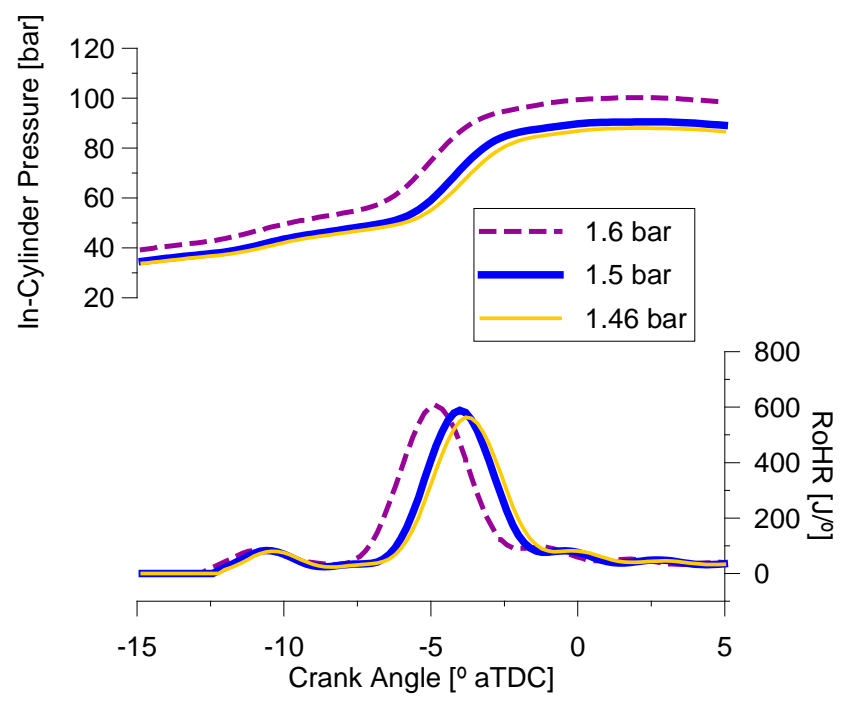

Figure 6. Instantaneous Combustion Data of Case 3 with 10\% Intake Oxygen Concentration.

Figure 7 shows combustion analysis statistics taken from each test case. The peak adiabatic flame temperatures were quite similar within each intake oxygen concentration, with only slight variations for changes to intake pressure. The highest intake oxygen concentration test points (Case 1 with 12\% intake $\mathrm{O}_{2}$ concentration) produced peak adiabatic flame temperatures between 2200 and $2225 \mathrm{~K}$, with lower intake oxygen concentration Cases 2 and 3 at even lower peak adiabatic flame temperatures. It has been shown important to be near or below peak adiabatic flame temperatures of $2200 \mathrm{~K}$ to take advantage of the low $\mathrm{NO}_{\mathrm{x}}$ emissions benefits of premixed diesel low temperature combustion (LTC).[6] As seen in the instantaneous combustion data, advances of the HTHR caused higher peak cylinder pressures at top dead center (TDC). Thus higher peak in-cylinder pressures were realized with higher intake pressure. There was a loose trend of higher peak RoHR with increased intake pressure. This is indicative of slightly higher combustion noise and faster combustion reaction rates. 

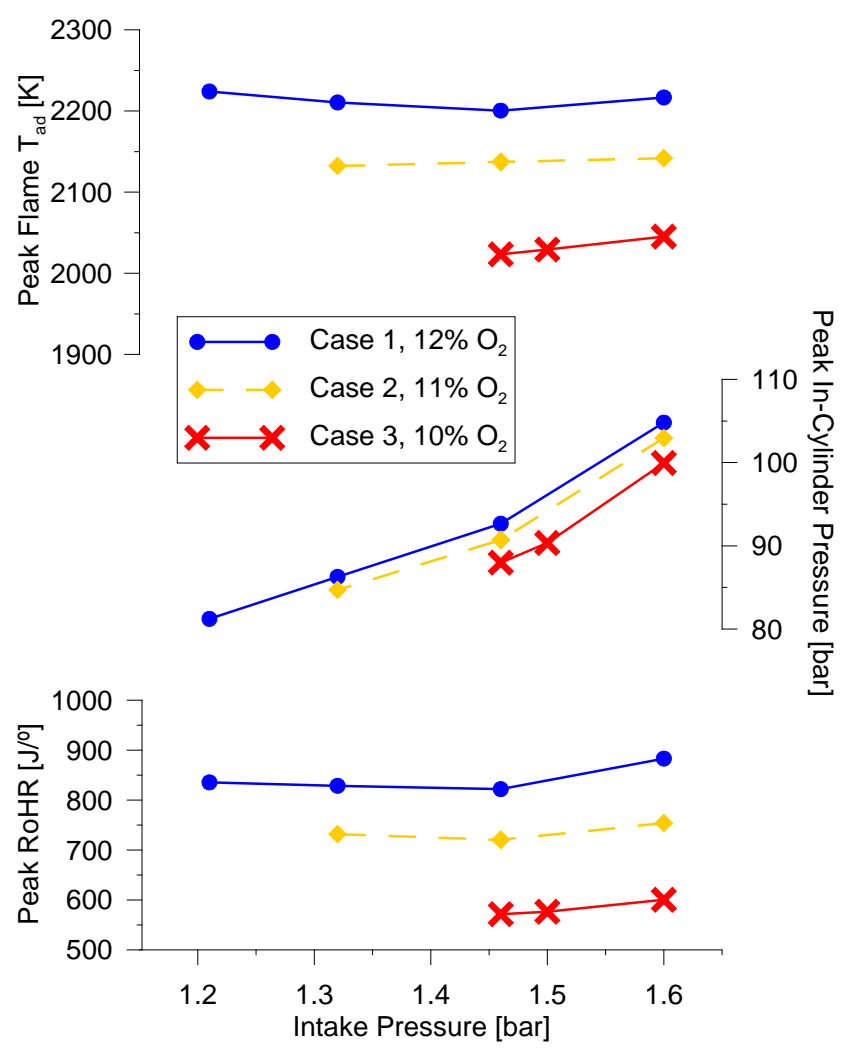

Figure 7. Combustion Statistics for Each Test Case.

\subsection{GENERAL EMISSIONS}

The levels of commonly measured Diesel engine emissions such as NOx, opacity-based PM, HC, and CO are shown in relation to their respective regulation limits in Figure 8. The engine-out $\mathrm{NO}_{\mathrm{x}}$ and $\mathrm{PM}^{\mathrm{s}}$ emissions for all test cases were low enough to comply with US2010 and proposed Euro VI emissions regulations. The changes in intake oxygen concentration between the three test cases proved to have a larger influence on the $\mathrm{NO}_{x}$ emissions than the changes to intake pressure within each test case. Consistent with other researchers, increased intake pressure caused a significant decrease in $\mathrm{HC}, \mathrm{CO}$, and PM mass emissions. Reasons for the nearly exponential decreases in these emissions will be further analyzed in the following sections. 


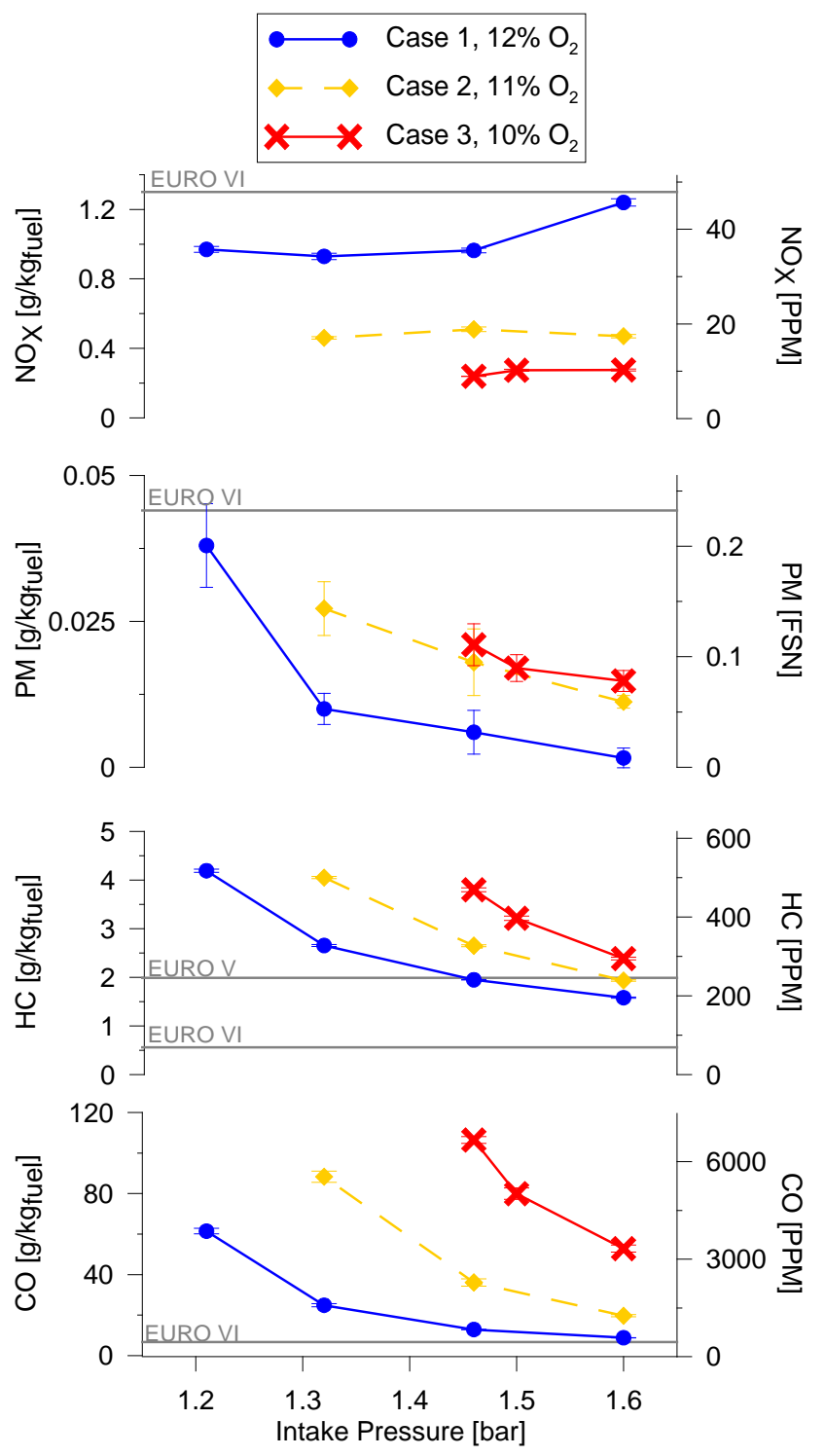

Figure 8. General Emissions for Each Test Case.

\subsection{PM FORMATION \& OXIDATION PARAMETERS}

Various parameters have been calculated and represented in the following Figure 9 to provide insight into the $\mathrm{HC}, \mathrm{CO}$, and PM mass formation and oxidation characteristics in the combustion chamber, at least on a relative basis. For in-cylinder PM formation to occur, two local conditions are necessary: high temperatures and local fuel richness.[30] The maximum adiabatic flame temperature of each test point has been represented in Figure 7. This shows that in all test cases there were temperatures high enough to promote the processes of incylinder particle formation.

The other key component for in-cylinder particle formation, local richness, is dependent on the amount of fuel and air premixing allowed before the start of combustion and the level of liquid fuel deposition on the combustion chamber surface. The duration from the $\mathrm{EOI}$ to the SOC, and the maximum local fuel air equivalence ratio (approximated by the 1D free spray model) at the start of combustion $\left(\Phi_{\mathrm{soc}}\right)$ provide qualitative information as to the level of fuel and air premixing in the main volume of the combustion chamber before the start of combustion. It can be seen in Figure 9 the decrease of CAD duration from the EOI to the SOC for increased intake pressure. This means that less time was available for fuel and air premixing with higher intake pressures. It was also observed that even in the shortest ignition delay engine operating condition, there were still more than 4 CAD between the end of injection and the start of the HTHR.

The liquid length overlap (as approximated by the 1D free spray model) is useful in estimating the relative levels of liquid fuel deposited on the piston bowl surface which would suspectedly be burned later in a diffusive-type of pool-fire combustion, that has been shown to be the source of high in-cylinder particle formation.[35,46-49]

Finally, the temperature at the end of combustion is a useful parameter to examine the relative levels of particle oxidation occurring late in these single-injection premixed combustion processes. Since there is high uncertainty involved in calculating the exact CAD where the combustion had completed and determining the adiabatic flame temperature at that point, the adiabatic flame temperature after $85 \%$ fuel mass burned (Flame $\mathrm{T}_{\mathrm{ad}} \mathrm{85}$ ) has instead 
been used to indicate the relative level of in-cylinder particle oxidation occurring towards the end of the combustion process.

Being that the changes to the maximum adiabatic flame temperature (Figure 7 ) remained relatively small for changes in intake pressure, initial focus of the PM formation and oxidation discussion will be placed on the premixing time (SOC-EOI Duration) and approximated maximum local $\Phi_{\mathrm{SOc}}$ to better understand the levels of particle formation in the main volume of the combustion chamber. Figure 9 shows that increased intake pressure caused decreased fuel-air premixing time and a corresponding slight increase in the maximum local $\Phi_{\text {soc. }}$. These two characteristics normally would point to increased in-cylinder particle formation and engine-out PM emissions. But PM mass emissions were seen to nearly exponentially decrease with increased intake pressure in Figure 8. Therefore there must be another explication for the decrease in PM emissions with increased intake pressure if shorter premixing timing and increases in estimated maximum local $\Phi_{\text {soc }}$ didn't agree with the emissions measurements. (Although it should be noted that there was a relatively long period of premixing in all test cases such that the maximum approximated local $\Phi_{\mathrm{soc}}$ of all test points was still less than 2.9 (Figure 3). So perhaps the changes in ignition delay and local $\Phi_{\text {Soc }}$ seen had a less significant influence on the PM formation.)

When analyzing the spray liquid length overshoot past the piston bowl surface (qualitative means of relating the level of fuel wetting on the piston), increased intake pressure had a strong effect on increasing the charge air density and reducing the level of fuel deposition on the piston bowl. This reduced fuel deposition would have most likely decreased the mass of fuel which would have been burned in a locally-rich diffusive-burn pool fire on the surface of the piston bowl, thus helping decrease in-cylinder particle formation during the combustion process.

The final PM combustion parameter from Figure 9 not yet discussed is the adiabatic flame temperature after $85 \%$ of the fuel mass burned. This parameter gives a relative means of approximating the levels of particle (as well as $\mathrm{CO}$ and $\mathrm{HC}$ ) oxidation towards the end of the combustion process. In all cases, increased intake pressure caused an increase in the Flame $\mathrm{T}_{\mathrm{ad}} 85$ by more than $140 \mathrm{~K}$. This increase in the combustion temperatures late in the combustion process means oxidation rates were relatively higher to thus oxidize more particles in the higher intake pressure cases. Therefore reduced fuel liquid length overshoot and increased Flame $T_{a d} 85$ help support that there was reduced fuel deposition on the piston surfaces (less particle formation) and increased in-cylinder particle oxidation with higher intake pressures to explain the overall decrease in engine-out PM mass emissions. In the next section, the changes in PM mass emissions will be analyzed on a particle size basis by particle size distribution measurements of each test case. 


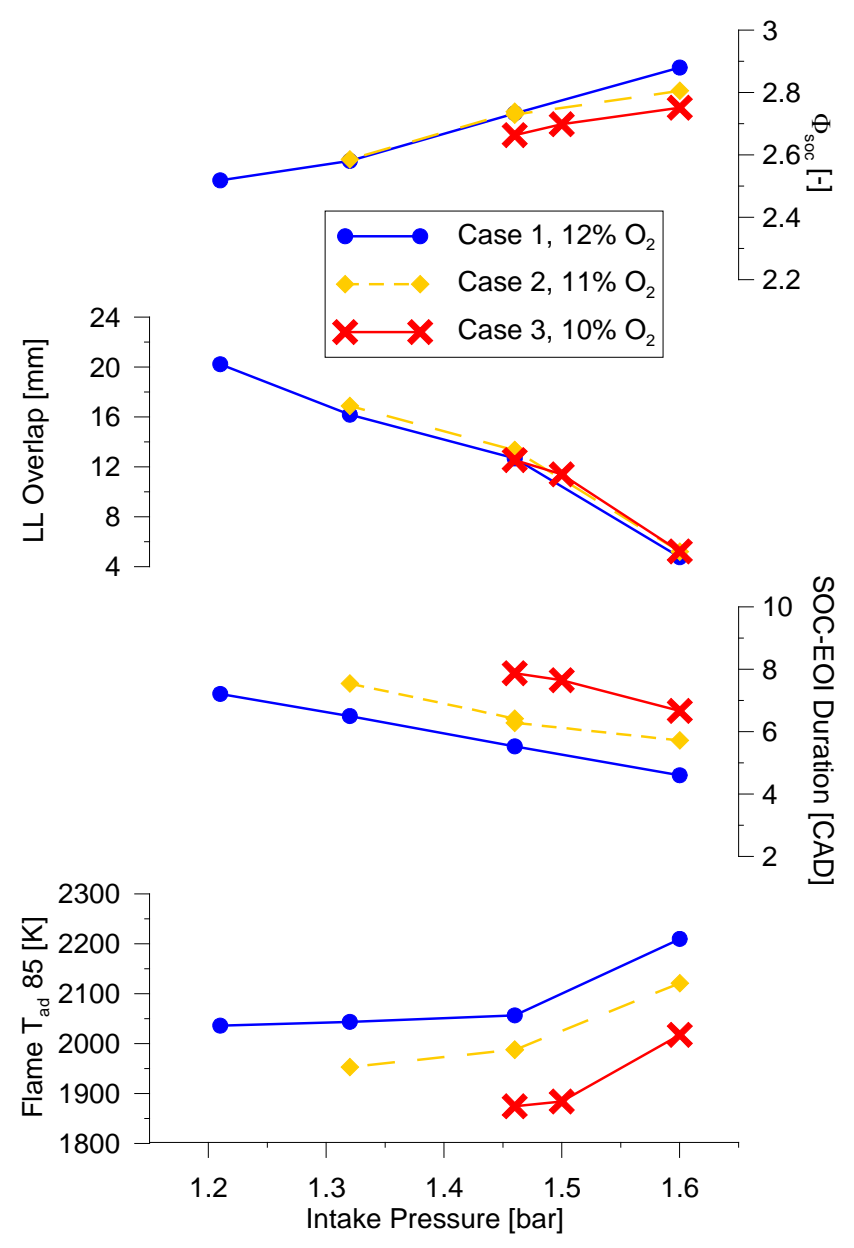

Figure 9. Parameters Which Indicate the Relative Levels of In-Cylinder PM Formation and Oxidation.

\subsection{PARTICLE SIZE DISTRIBUTIONS}

Exhaust particle size distributions were measured for each engine test point and are represented in Figure 10. Graphs A, B, and C show the results of Cases 1, 2, and 3, respectively. In each test case (each intake oxygen concentration condition), increased intake pressure was shown in general to decrease particle number emissions. This was also seen in the total particle number concentration characteristics shown in Figure 11.

In Case 1 (Graph A) and Case 2 (Graph B), increased intake pressure caused a large decrease in particles larger than $100 \mathrm{~nm}$. Simply based on geometry, the biggest particles will have an exponentially higher effect on the total PM mass than the smallest particles.[44] For this reason, a large decrease in PM mass emissions can be expected in cases 1 and 2 only by analyzing their particle size distributions.

The explanations discussed regarding the particle formation and oxidation parameters in Figure 9 are reaffirmed when looking at the effects of intake pressure on the particle size distribution measurements. Interestingly, the strongest change in the shape (curvature) of the particle size distributions occurred between the two lowest intake pressures, 1.2 bar and 1.32 bar in Case 1 (Graph A). This shape change of increased large particles and decreased small particles is also reflected in the particle geometric mean diameters from each test case in Figure 11. Note that the effect of intake pressure on the particle geometric mean diameter was most importantly seen for the intake pressure increase from 1.2 to 1.32 bar. Although 1.2 bar intake pressure had the lowest calculated $\Phi_{\text {soc }}$ (due to it's long ignition delay) of Case 1 , it also had the highest predicted distance of fuel liquid length overlap past the piston surface of any test case. This reinforces the argument that decreased fuel spray impingement on the piston had an important effect on the decrease in PM mass emissions (likewise a decrease in the largest particles).

It is traditionally known that the smallest particles of the size distribution are mostly composed of volatile material which condensed during exhaust cooling.[44,45] These smallest particles could have solid cores, which provide surface area for the volatile material to preferentially condense on. Or these small volatile particles could be purely composed of volatile material if there isn't enough particle surface area available, and the volatile material partial pressures allow it. Therefore the increase in largest particles and simultaneous decrease in smallest particles seen from 1.32 to 1.2 bar intake pressure could possibly be explained by a sufficient increase in large particle surface area to better accommodate the condensation of volatile material that is later not available to form the smallest particles of the size distribution. 
While decreased fuel liquid impingement with higher intake pressure seems to have the primary effect of decreased large particles (with initially an important secondary effect of increased small particles), improved latecycle oxidation seems it would affect all of the particle size distribution. Higher $\mathrm{T}_{\mathrm{ad}} 85$ temperatures with higher intake pressure meant that there was improved oxidation of large soot aggregate particles as well as the volatile material which could later condense to form additional particles as the exhaust cooled. For that reason, improvements to solid particle and volatile material oxidation with higher intake pressure can be seen throughout the particle size distribution. The improved late-cycle oxidation could especially be important when the particle size distributions decreased in particle concentration, but did not change in shape (curvature).

Decreased intake oxygen concentration from Case 1 to $3(12 \%$ to $10 \%)$ is shown to have changed the shape of the particle size distributions from relatively flat for particles smaller than $35 \mathrm{~nm}$ in Case 1 to a more inverse parabolic shape in the lowest oxygen concentration Case 3 (Figure 10). In addition to the change in the shape of the particle size distributions, there was also a general trend of increased particle numbers and a small increase in geometric mean diameter from $12 \%$ to $10 \%$ intake oxygen concentration (Figure 11). These observations are in agreement with [17].

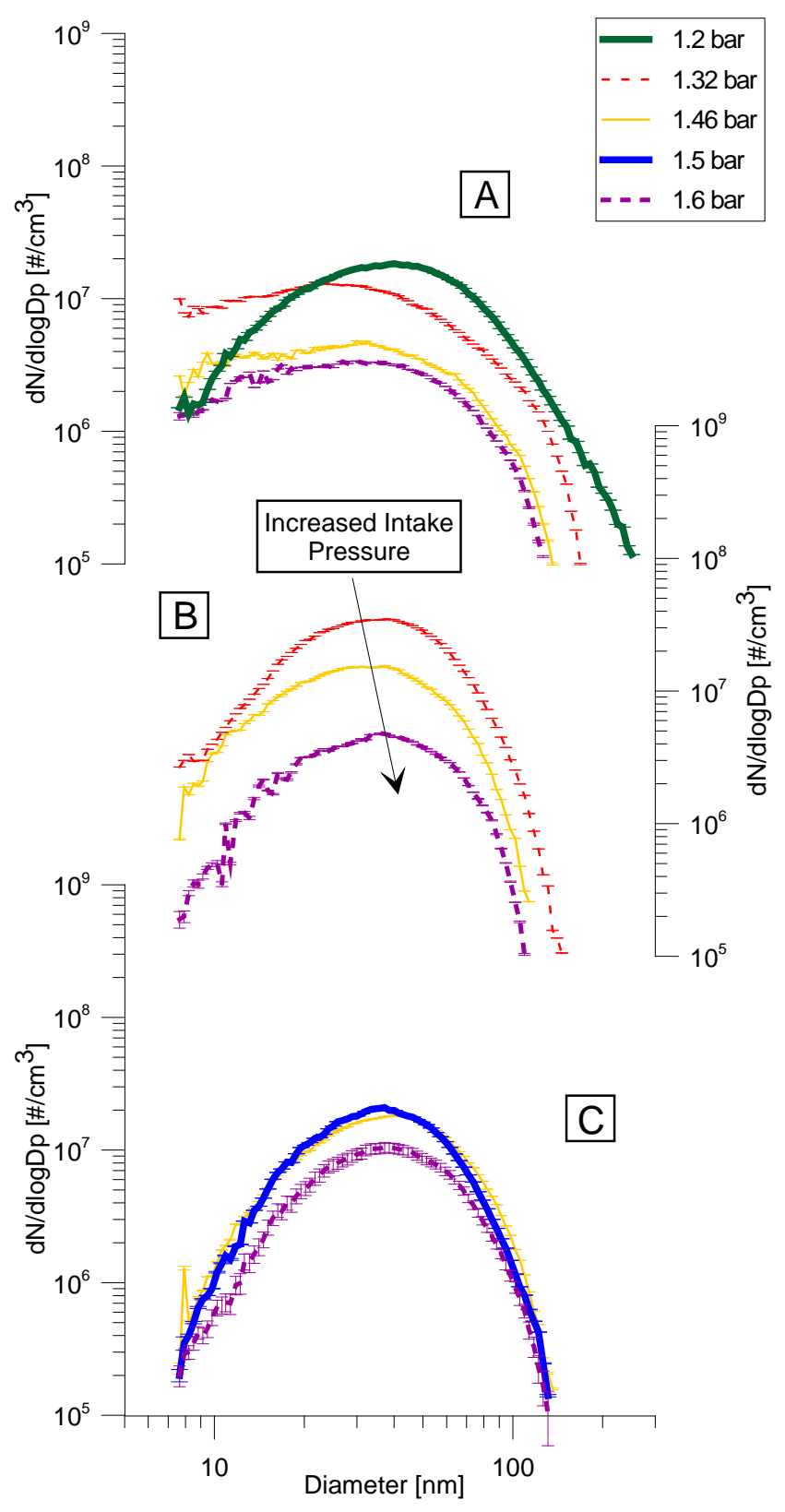

Figure 10. Particle Size Distribution Measurements for the $12 \% \mathrm{O}_{2}$ Case 1 (A), $11 \% \mathrm{O}_{2}$ Case 2 (B), and $10 \% \mathrm{O}_{2}$ Case 3 (C). (Particle concentrations were corrected for dilution air background particles.) 


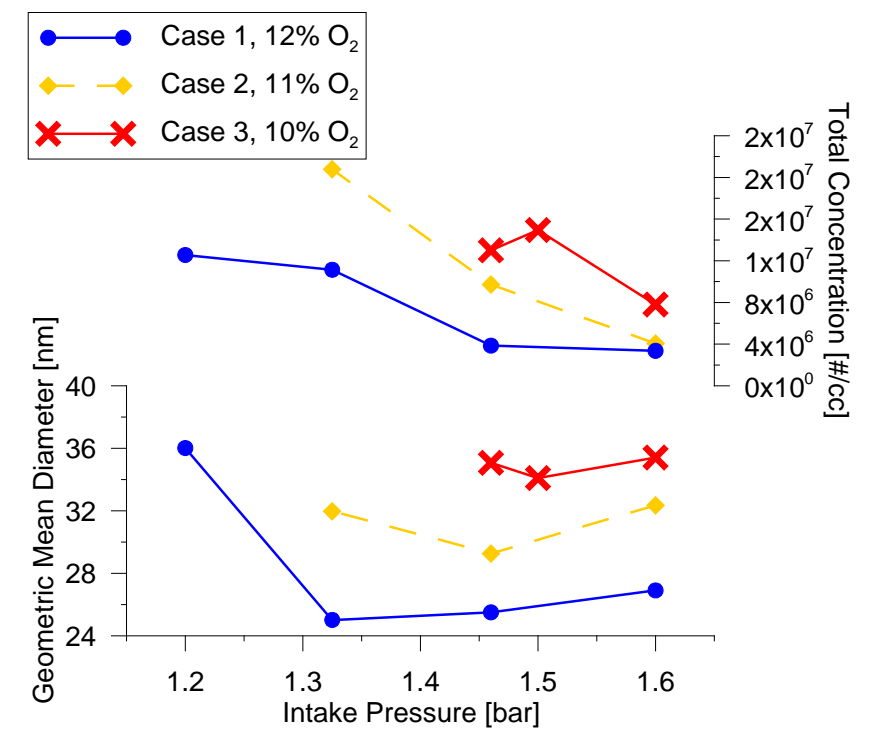

Figure 11. Particle Emissions Size and Number Statistics.

\section{CONCLUSIONS}

Measurements of gaseous and particulate (mass, size, and number) emissions from premixed Diesel LTC have been investigated from three intake oxygen concentrations, with intake pressures ranging from 1.2 to 1.6 bar. Increased intake pressure in Case $1\left(12 \%\right.$ Intake $\left.\mathrm{O}_{2}\right)$ produced the following reductions on the emissions: $\mathrm{CO}$ (85\%), HC (62\%), PM mass (96\%), and particle number (73\%). EURO VI PM mass and $\mathrm{NO}_{\mathrm{x}}$ emissions standards were achieved for all intake pressures, but none of the intake pressures were able to achieve EURO $\mathrm{VI} \mathrm{CO}$ and $\mathrm{HC}$ emissions limits.

By use of fluid-dynamic and thermodynamic calculations, the large decreases in particle mass and number emissions with increased intake pressure were more closely investigated. A visual representation of the conclusions has been produced in Figure 12 to aid in their explanations. In particular, the conclusions will consider Case $1\left(12 \%\right.$ Intake $\left.\mathrm{O}_{2}\right)$. Higher in-cylinder charge air density caused up to $25 \%$ faster premixing rates (improved premixing quality) in the main area of the combustion chamber, as seen through the 1D free spray simulations in Figure 3. But total premixing times before SOC were reduced by $35 \%$ due to the mixture arriving to auto-ignition conditions sooner, thus increasing the maximum local $\Phi_{\text {soc }}$ by $15 \%$ (from 2.5 to 2.9). Therefore, without taking wall effects into account, one would expect higher particle formation in the main area of the combustion chamber with higher intake pressure due to the rise in $\Phi_{\text {soc }}$.

But it was measured that engine-out particle mass and number emissions decreased significantly with higher intake pressure. It was found that this result had a twofold explanation, coming from reduced fuel deposition on the piston bowl and increased particle oxidation late in the combustion. The predicted fuel spray liquid length overshoot past the piston bowl surface (and presumed amounts of fuel deposition on the piston bowl surface for later pool fires) in this engine was decreased by $75 \%$ (from 20.0 to $4.8 \mathrm{~mm}$ ) when intake pressure increased from 1.2 to 1.6 bar. Simultaneously, the $T_{\text {ad }} 85$ (late-cycle oxidation quality) increased by $175 \mathrm{~K}$ (from 2035 to 2210K) for increased intake pressure from 1.2 to 1.6 bar, a 125\% increase over the critical 1900K below which particle oxidation is greatly decreased. [Kamimoto, SAE 880423] 


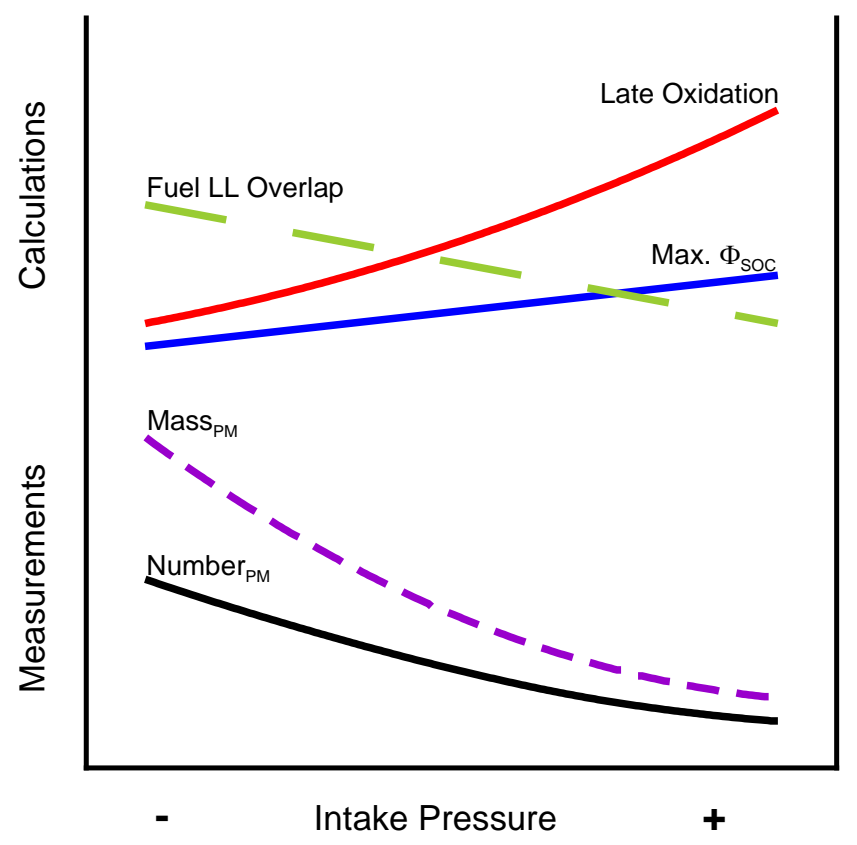

Figure 12. Visual Representation of the Effects of Intake Pressure on Premixed Diesel LTC PM Emissions.

\section{ACKNOWLEDGMENTS}

The authors would like to sincerely thank Gabriel Alcantarilla, Steeve Robert, Miguel Peña Sánchez, Ricardo Novella, and Simon Arthozoul for their much appreciated help in experimental data collection and postprocessing. This research has been carried out in the frame of the project PROMETEO/2010/032 supported by the Generalitat Valenciana. Financial support of Christopher Kolodziej was provided by the Spanish Ministry of Education (Formación del Profesorado Universitario). This publication comes from a portion of the doctoral thesis work of Christopher Kolodziej.

\section{REFERENCES}

1. Y. Takeda, N. Keiichi, N. Keiichi, SAE Paper 961163, 1996.

2. H. Suzuki, N. Koike, H. Ishii, M. Odaka, SAE Paper 970313, 1997.

3. H. Yokota, Y. Kudo, H. Nakajima, T. Kakegawa, T. Suzuki, SAE Paper 970891, 1997.

4. N. Shimazaki, H. Akagawa, K. Tsujimura, SAE Paper 1999-01-0181, 1999.

5. S. Kimura, O. Aoki, H. Ogawa, S. Muranaka, Y. Enomoto, SAE Paper 1999-01-3681, 1999.

6. K. Akihama, Y. Takatori, K. Inagaki, S. Sasaki, A.M. Dean, SAE Paper 2001-01-0655, 2001.

7. S. Kimura, O. Aoki, Y. Kitahara, E. Aiyoshizawa, SAE Paper 2001-01-0200, 2001.

8. R.M. Wagner, J.B. Green Jr., T.Q. Dam, K.D. Edwards, J.M. Storey, SAE Paper 2003-01-0262, 2003.

9. K. Okude, K. Mori, S. Shiino, T. Moriya, SAE Paper 2004-01-1907, 2004.

10. T. Raatz, E. Mueller, SAE Paper 2001-01-3576, 2001.

11. C.S. Sluder, R.M. Wagner, J.M.E. Storey, S. Lewis, SAE Paper 2005-01-3844, 2005.

12. C. Kolodziej, E. Wirojsakunchai, D.E. Foster, N. Schmidt, T. Kamimoto, T. Kawai, M. Akard, T. Yoshimura, JSAE Paper 20077142, SAE Paper 2007-01-1945, 2007.

13. J.M.E. Storey, S.A. Lewis Sr., J.E. Parks II, J.P. Szybist, T.L. Barone, V.Y. Prikhodko, SAE Paper 2008-012431, 2008.

14. K.C. Natti, N.A. Henein, Y. Poonawala, W. Bryzik, SAE Paper 2008-01-1086, 2008.

15. J. Benajes, R. Novella, S. Arthozoul, C. Kolodziej, SAE Paper 2010-01-1121, SAE Int. J. Fuels Lubr. 3 (2010) 567-581.

16. J. Benajes, R. Novella, S. Arthozoul, C. Kolodziej, Poster and Extended Abstract, $14^{\text {th }}$ ETH-Zurich Conference on Combustion Generated Nanoparticles, Aug., 2010.

17. F. Payri, J. Benajes, R. Novella, C. Kolodziej, SAE Paper, 2011-01-1355, SAE Int. J. Engines 4 (2011) 18881902.

18. C. Noehre, M. Andersson, B. Johansson, A. Hultqvist, SAE Paper 2006-01-3412, 2006.

19. W.F. Colban, P.C. Miles, S. Oh, SAE Paper 2007-01-4063, 2007.

20. W. Albrecht, U. Dohle, R. Gombert, J. Krauss, R. Leonhard, P. Wannenwetsch, "Das innovative Bosch Common Rail System für die neue Generation von schweren DaimlerChrysler Nutzfahrzeug-Dieselmotoren," 28. Internationales Wiener Motorensymposium, 2007.

21. M. Lapuerta, O. Armas, J.J. Hernández, Appl. Therm. Eng., 19 (5) (1999) 513-529. 
22. F. Payri, S. Molina, J. Martín, O. Armas, Appl. Therm. Eng., 26 (2-3) (2006) 226-236.

23. R. J. B. Way, Proc. Inst. Mech. Eng., 190 (60) (1976) 686-697.

24. W. Bosch, SAE Paper 660749, 1966.

25. K. J. Baumgard, J. H. Johnson, SAE Paper 960131, 1996.

26. P. Bielaczyc, J. Merkisz, M. Kozak, SAE Paper 2002-01-2219, 2002.

27. K. Mitchell, D. E. Steere, J. A. Taylor, B. Manicom, J. E. Fisher, E. J. Sienicki, C. Chiu, P. Williams, SAE Paper 942053, 1994.

28. Z. G. Liu, V. N. Vasys, D. B. Kittelson, Environ. Sci. Tech., 41 (18) (2007) 6479-6483.

29. C. J. J. Den Ouden, R. H. Clark, L. T. Cowley, R. J. Stradling, W. W. Lange, C. Maillard, SAE Paper 942022, 1994.

30. D. R. Tree, K. I. Svensson, Prog. Energ. Combust. 33 (2007) 272-309.

31. I. Abdul-Khalek, D. B. Kittelson, F. Brear, SAE Paper 1999-01-1142, 1999.

32. TSI Incorporated, Scanning Mobility Particle Sizer ${ }^{\text {TM }}$ (SMPS ${ }^{\top M}$ ) Spectrometer User's Manual, P/N 1930038, Revision G, October, 2006.

33. J. V. Pastor, J. J. López, J. M. García, J. M. Pastor, Fuel, 87 (2008) 2871-2885.

34. J. M. Desantes, J. V. Pastor, J. M. García-Oliver, J. M. Pastor, Combust. Flame, 156 (2009) 234-249.

35. J. Benajes, J. M. García-Oliver, R. Novella, C. Kolodziej, Fuel, (2011) doi:10.1016/j.fuel.2011.09.014.

36. C. S. Sluder, R. M. Wagner, S. A. Lewis, J. M. E. Storey, SAE Paper 2004-01-0114, 2004.

37. R. Opat, Y. Ra, M. A. Gonzalez D., R. Krieger, R. D. Reitz, D. E. Foster, R. P. Durrett, R. M. Siewert, SAE Paper 2007-01-0193, 2007.

38. S. V. Bohac, M. Han, T. J. Jacobs, A. J. López, D. N. Assanis, P. G. Szymkowicz, SAE Paper 2006-01-0201, 2006.

39. P. Merritt, Y. Huang, M. Khair, J. Pan, SAE Paper 2006-01-3307, 2006.

40. C. P. Koci, Y. Ra, R. Krieger, M. Andrie, D. E. Foster, R. M. Siewert, R. P. Durrett, I. Ekoto, P. C. Miles, SAE Paper 2009-01-0928, 2009.

41. J. T. Kashdan, S. Mendez, G. Bruneaux, SAE Paper 2007-01-1836, 2007.

42. M. P. B. Musculus, T. Lachaux, L. M. Pickett, C. A. Idicheria, SAE Paper 2007-01-0907, 2007.

43. T. V. Johnson, SAE Paper 2010-01-0301, 2010.

44. D. B. Kittelson, J. Aerosol Sci. 29 (5) (1998) 575-588.

45. R. M. Montajir, T. Kawai, Y. Goto, M. Odaka, M., SAE Paper 2005-01-0187, 2005.

46. T. Fang, R. E. Coverdill, C. F. Lee, R. A. White, SAE Paper, 2007-01-0203, 2007.

47. G. C. Martin, C. J. Mueller, D. M. Milam, M. S. Radovanovic, C. R. Gehrke, SAE Paper, 2008-01-2400, 2008.

48. S. Kook, L. M. Pickett, M. P. B. Musculus, SAE Paper, 2009-01-1356, 2009.

49. L. M. Pickett, S. Kook, T. C. Williams, SAE Paper, 2009-01-0839, 2009.

\section{CONTACT}

Christopher Kolodziej

Telephone: +34-963877007.

Fax: +34-963877659.

Email: chko@mot.upv.es, ckolodziej@hotmail.com

Jesús Benajes

Email: ibenajes@mot.upv.es 
